\title{
Continuous Renal Replacement Therapy with the Adsorbing Filter oXiris in Septic Patients: A Case Series
}

\author{
Franco Turani $^{\mathrm{a}, \mathrm{b}}$ Riccardo Barchetta ${ }^{\mathrm{a}}$ Mauro Falco $^{\mathrm{a}}$ Silvia Busatti ${ }^{\mathrm{a}}$ \\ Luca Weltert ${ }^{c}$ \\ ${ }^{a}$ Anesthesia and Intensive Care, Aurelia Hospital and European Hospital, Rome, Italy; ${ }^{b}$ Adjunt Professor of \\ Anesthesia and Intensive Care, University of Tor Vergata, Rome, Italy; ${ }^{C}$ Cardiac Surgery European Hospital Rome, \\ Rome, Italy
}

\section{Keywords}

Sepsis/septic shock · Acute kidney injury · Adsorbing filters · Cytokines · Endotoxins

\section{Abstract}

Background: Extracorporeal treatment may be useful during sepsis, but definitive recommendations are lacking. Aim of this study is to review retrospectively the medical records of septic patients submitted to continuous renal replacement therapy (CRRT) with the adsorbing membrane oXiris and evaluate (1) the safety of the device, (2) the cardiorenal response, and (3) the immunological response. Materials and Methods: The medical records of 60 septic patients submitted to CRRT with the membrane oXiris from April 2011 to December 2018 have been reviewed. The adsorbing membrane oXiris ${ }^{\circledR}$ (Baxter, IL, USA) was used through a Prisma plataform (Prismaflex - Baxter, IL, USA). At basal time (T0), at $24 \mathrm{~h}$ (T1), and at the end of the treatment (T2) were analyzed the clinical data, the cytokines, and the time course of endotoxin. Results: Sixty patients were included in the study. In total, $85 \%$ of patients had acute kidney injury (AKI). Every
CRRT treatment was of $72 \pm 13 \mathrm{~h}$, with the consumption of $3.2 \pm 1$ filters. No AE events were reported. The main cardiorenal and respiratory parameters improved with a decrease of the noradrenaline dosage. Cytokines, procalcitonin, and endotoxin activity assay decreased too. SOFA total improved from $12.4 \pm 2$ to $9 \pm 2$. Conclusion: In sepsis/septic shock patients with AKI, CRRT with the adsorbing membrane oXiris may be safe and improves the cardiorenal - function and the clinical condition. The effect on cytokines and endotoxin may explain in part these results. A RCT is warranted to confirm these data.

(C) 2019 The Author(s) Published by S. Karger AG, Basel

\section{Introduction}

Sepsis and septic shock are the leading cause of mortality in critical care patients, but neither the hemodynamic approach (e.g., Svo2 protocol) nor new pharmacological agents have shown any positive effect on mortality. Thus, many studies are evaluating, with conflicting results, the

\begin{tabular}{ll}
\hline KARGER & $\begin{array}{l}\text { (c) } 2019 \text { The Author(s) } \\
\text { Published by S. Karger AG, Basel }\end{array}$ \\
E-Mail karger@karger.com & $\begin{array}{l}\text { This article is licensed under the Creative Commons Attribution- } \\
\text { NonCommercial-NoDerivatives 4.0 International License (CC BY- } \\
\text { NC-ND) (http://www.karger.com/Services/OpenAccessLicense). } \\
\text { wwwage and distribution for commercial purposes as well as any dis- } \\
\text { tribution of modified material requires written permission. }\end{array}$
\end{tabular}

Dr. Franco Turani, MD

Department of Anestesia

Intensive Care Aurelia Hospital Rome

Via Aurelia 860, IT-00100 Rome (Italy)

E-Mail turani.franco44@gmail.com 
possibility to adsorb by extracorporeal devices the most important proinflammatory mediators (Endotoxin, Il6, Procalcitonin, HMBG1) to prevent organ failures $[1,2]$. Among many emerging adsorption techniques, continuous renal replacement therapy (CRRT) with the membrane oXiris achieves an optimal renal purification with the adsorption of cytokines, endotoxin, and other inflammatory mediators [3].

Malard et al. [4] found in a "in vitro" study that, at the difference with other devices used currently in septic patients (Toray ${ }^{\circledR}$ and Cytosorb ${ }^{\circledR}$ ), the oXiris filter is able to remove either the cytokines and the endotoxin. This important anti-inflammatory action translated in a better hemodynamic, metabolic, and respiratory response in animals treated with the oXiris filter [3].

Few clinical studies, however, investigated the effect of the oXiris filter on septic patients, and many of these are case series or observational and preclude any conclusion about the efficacy of the device during sepsis/septic shock [5].

Very recently, however, Broman et al. [6] in a RCT have shown that the oxirs filter may reduce either the endotoxin concentration nor the plasmatic IL-6 in septic patients submitted to CRRT, although the latter effect was not superior to the AN69ST membrane. Turani et al. [7], too, in a propensity match-case control, study reported similar results on a septic population with acute kidney injury (AKI).

In spite of this growing interest for the effects of the oXiris filter in septic patients, we sought to review our clinical experience of the last 8 years on septic patients submitted to CRRT with this device. The aim of this case series review is to evaluate (1) the safety of the device, (2) the effect on the renal function, (3) the effect on the cardiac and respiratory parameters, and (4) the effect on the immunological parameters, including the changes of endotoxin.

\section{Patients and Methods}

\section{Study Design and Patients}

A retrospective observational study was carried out from January 2011 to December 2018. This case series was conducted at the Surgical-Medical Intensive Care of Aurelia Hospital and at the Cardiac Surgical Intensive Care of European Hospital in Rome. All the medical records of septic patients submitted to CRRT with the filter oXiris were reviewed. All patients or their relatives gave signed informed consent for retrospective data evaluation. The study was approved by the Ethics regional Committee of Saint Camillo Hospital in Rome. Patients with sepsis/septic shock were enrolled in the study using criteria according to Surviving Sepsis Campaign Guidelines. Patients were initially treated following the
Surviving Sepsis Guidelines and then submitted to CRRT with the filter oXiris whether any hemodynamic and/or renal improvement was observed by the physician in charge, despite maximal therapy.

\section{Continuous Renal Replacement Therapy Protocol}

CRRT was performed in continuous veno-venous hemodialysis (CVVHDF) using the adsorbing membrane oXiris ${ }^{\circledR}$ (Baxter, USA) through a Prismaflex CRRT system ${ }^{\circledR}$ (Baxter, USA). Blood flow rates were kept between 100 and $150 \mathrm{~mL} / \mathrm{min}$, while the dialysis doses were in the range of $20-30 \mathrm{~mL} / \mathrm{kg} / \mathrm{h}$, according to the clinical condition. A venous double lumen catheter (Fr 11, Gambro, Sweden) was inserted in the femoral venous or internal jugular vein under echographic guidance.

\section{Anticoagulation}

A continuous infusion of nonfractionated heparin or citrate was used for the anticoagulation of the circuit. Heparin was used at the dosage of $5-15 \mathrm{UI} / \mathrm{Kg} / \mathrm{h}$. The heparin dosage was adjusted on the data of ACT and TEG (Tromboelastography, Haemonetics ${ }^{\circledR}$, USA), Antitrombin III was infused to reach an AT III concentration $>70 \%$.

In patients with loco regional anticoagulation, a prepump citrate infusion was used to anticoagulate the circuit: a sterile citratecontaining solution without calcium was infused in predilution mode with the following composition (in mmol/L): Citrate 18, $\mathrm{Na}$ 140, and $\mathrm{Cl} 86$ (Prisma citrate ${ }^{\circledR} 18.0$ Gambro). In postdilution, a sterile saline solution containing calcium chloride $2 \%$ was infused to maintain postfilter $\mathrm{Ca}++0.6-0.8 \mathrm{meq} / \mathrm{L}$, arterial $\mathrm{Ca}++1-1.5$ $\mathrm{meq} / \mathrm{L}$, and $\mathrm{Ca} / \mathrm{Ca}++<2.1$. In these patients, TEG monitoring was used to control anticoagulation at arterial site and postfilter. Blood gas analysis was used to check $\mathrm{Ca}++$ arterial, $\mathrm{Ca}++$ prepump, $\mathrm{Ca} /$ $\mathrm{Ca}++$, lactate, bicarbonate, $\mathrm{Mg}$, and phosphate.

\section{Data Collection}

For the enrolled patients, the clinical, biochemical, and microbiological data, Apache score II, SOFA, and KDIGO score were recorded. All clinical data are stored on the clinical informatic plataform Clinic Data Pro (System Line - Empoli, Italy), and the microbiological, immunological, and coagulation data are stored on the laboratory informatic plataform -Modulab Gold Italy - (Werfen, UK).

All patients were continuously monitored for mean arterial pressure, central venous pressure, heart rate, blood gas analysis, diuresis, lactate, and ventilation parameters.

Selected patients, as decided by the attending physician, were monitored with a continuous cardiac output system (EV $1,000^{\circledR}$, Edwards, USA). The dose of vasoactive/vasopressor agents is expressed in $\mu \mathrm{g} / \mathrm{kg} / \mathrm{min}$. The plasma levels of IL-6 and IL-10 were measured using enzyme-linked immunosorbent assay kits according to the manufacturer's instructions (R\&D Systems, Minneapolis, MN, USA). PCT was detected by enzyme-linked fluorescence assay (MINI VIDAS; bioMérieux, Marcy-l'Étoile, France). Plasma endotoxin activity was evaluated by endotoxin activity assay (EAA - Spectral Diagnostic Toronto, Canada). Elevated plasma endotoxin activity was defined as EAA $>0.6 \mathrm{EU} / \mathrm{mL}$. For every patients, we recorded the number and the hours of sessions of CRRT.

The main cardiorespiratory data, the metabolic and the immunological changes were evaluated at basal time (T0) after $24 \mathrm{~h}$ (T1) and at the end of the treatment (T2). Isolated microorganisms have 
Table 1. Main clinical data of the study population at the beginning of the treatment with oXiris filter

\begin{tabular}{ll}
\hline Gender, male/female & $40 / 20$ \\
Age, years & $68 \pm 9$ \\
SOFA total & $13 \pm 2$ \\
APACHE 2 & $25 \pm 5$ \\
AKIN stage on starting of CRRT & \\
$\quad$ Stage 3 & 20 \\
$\quad$ Stage 2 & 20 \\
Stage 1 & 10 \\
No AKI & 10 \\
\hline
\end{tabular}

AKI, acute kidney injury; CRRT, continuous renal replacement therapy.

Table 2. Hemodynamic and respiratory changes during CRRT with the membrane oXiris

\begin{tabular}{lccc}
\hline & T0 & T2 & $p$ value \\
\hline $\mathrm{HR}, \mathrm{b} / \mathrm{min}$ & $88 \pm 9$ & $66 \pm 10$ & \\
$\mathrm{MAP}, \mathrm{mm} \mathrm{Hg}$ & $63 \pm 12$ & $79 \pm 13$ & $<0.001$ \\
$\mathrm{CVP}, \mathrm{mm} \mathrm{Hg}$ & $10 \pm 3$ & $13 \pm 4$ & \\
Noradrenaline, $\mu \mathrm{g} / \mathrm{kg} / \mathrm{min}$ & $0.12 \pm 0.1$ & $0.05 \pm 0.01$ & $<0.01$ \\
$\mathrm{PaO}_{2} / \mathrm{FIO}_{2}$ & $215 \pm 80$ & $288 \pm 73$ & $<0.01$ \\
$\mathrm{PaCO}_{2}, \mathrm{~mm} \mathrm{Hg}$ & $45 \pm 8$ & $38 \pm 7$ & \\
$\mathrm{pH}$ & $7.36 \pm 0.10$ & $7.42 \pm 0.08$ & \\
\hline
\end{tabular}

CRRT, continuous renal replacement therapy.

Table 3. Metabolic changes during CRRT with the membrane oXiris

\begin{tabular}{lccl}
\hline & T0 & T1 & $p$ value \\
\hline Creatinine, mg/dL & $2.58 \pm 1$ & $1.15 \pm 0.5$ & $<0.0001$ \\
Urinary output, mL/24 h & $1,177 \pm 825$ & $2,066 \pm 1,300$ & $<0.001$ \\
$\mathrm{HCO}_{3}, \mathrm{meq} / \mathrm{L}$ & $21 \pm 2$ & $24 \pm 3$ & \\
Lactate & $2.7 \pm 1$ & $1.4 \pm 1$ & $<0.01$ \\
SOFA total & $12.4 \pm 2$ & $9 \pm 2$ & $<0.001$ \\
\hline
\end{tabular}

CRRT, continuous renal replacement therapy.

been reported. Antibiotic therapy was reviewed biweekly by the infectologist in charge, and the antibiotic dosage was adjusted on the data of CRRT.

\section{Statistical Analysis}

Data are expressed as absolute number and percentage for categorical variables, mean \pm SD for normally distributed variables, and as median (25th -75 th) for nonnormally distributed variables.
Values were compared using the Mann-Whitney or the Student $t$ test as appropriate Qualitative data were compared using the twotailed Fisher's exact test. SPSS version 21 (IBM, Armonk, NY, USA) and GraphPad Prism 5.01 software were used for all analyses.

\section{Results}

Between April 2011 and December 2018, a total of 60 patients with sepsis and septic shock submitted to CRRT with the oXiris filter entered the study, and all their clinical cards were reviewed. The treatments had a time duration of $74 \pm 36 \mathrm{~h}$ with a consumption of $3 \pm 1$ filters. In 40 patients, anticoagulation was achieved with citrate and in 20 patients with heparin.

Table 1 shows the basal clinical characteristics of the study group. In $85 \%$ of patients, CRRT with the oXiris filter started when sepsis was accompanied to acute renal failure, and only in $15 \%$ of patients, CRRT was started for nonrenal indications.

Table 2 shows the main cardiac and respiratory responses to the treatment. During the treatment, there was an improvement of the MAP and a decrease of the noradrenaline support. This was accompanied by an increase of the oxygenation index.

In Table 3, the main metabolic and renal data are shown. The treatment had an effect on the creatinine, on the urinary OFA.

The improvement of the cardiorenal function is associated with a decrease of IL-6, IL-10, and procalcitonin, as shown in Table 4. Also endotoxin decreased, when analyzed patients are with basal level of EAA $>0.6$.

Sixty percent of the patients enrolled in the study had a Gram-negative bacterial infection, 35 of the patients had a Gram-positive infection; $5 \%$ had a fungal infection; and in $10 \%$ of the patients, the infection source was not proven.

\section{Discussion}

The main finding of this case series study is that CRRT with the adsorbing membrane oXiris may be clinically feasible, has not adverse effects, and may be useful in septic patients with AKI and a cytokines storm. These data confirm some experimental studies, in which oXiris filter improved the renal function and decreased the inflammatory response during sepsis and AKI [3]. This is not surprising, as the adsorbing membrane oXiris is a deriva- 
Table 4. Immunological changes during CRRT with the membrane oXiris

\begin{tabular}{lccl}
\hline & T0 & T2 & $p$ value \\
\hline IL-6, pg/mL & $506 \pm 400$ & $126 \pm 92$ & $<0.001$ \\
IL-10, pg/mL & $106 \pm 57$ & $28 \pm 17$ & $<0.05$ \\
Procalcitonin, ng/mL & $30 \pm 36$ & $8 \pm 9$ & $<0.05$ \\
EAA, EAA/unit & $0.74 \pm 0.15$ & $0.58 \pm 0.18$ & $<0.01$ \\
\hline
\end{tabular}

EAA, endotoxin activity assay; CRRT, continuous renal replacement therapy.

tive of AN69 surface treated hemofilter with a high adsorption capacity for cytokines and other mediators [8]. In addition to the AN69ST, the oXiris filter has 3 time amount of polyethylene imine surface coating and 10 times greater amount of preimmobilized heparin.

In this way, oXiris has an antithrombogenity capacity, may adsorb also endotoxin, and retain its ability to adsorb cytokines. For these properties, oXiris-adsorbing membrane may be very useful to treat acute renal failure during sepsis: the kidney, in effect, not only is very sensitive to the proinflammatory mediators, but also promotes a detrimental crosstalk with other organ [9]. The strength of this treatment is that an anti-inflammatory action is linked to a renal purification in the early stage of sepsis, in which renal dysfunction exacerbates the production of cytokines and promotes multiorgan failure.

In effect, in this case series, CRRT with the oXiris filter started when AKI was already present and the proinflammatory reaction was severe. Creatinine and diuresis improved during the treatment: although these parameters are insensitive in patients with sepsis associated AKI, some recent studies indicated that urinary output is important and is associated with morbility and mortality, also during CRRT. Very recently, Jin et al. [10] recommended intensive monitoring of urinary output, especially in patients at high risk of AKI.

Anyway, during the treatment, we observed a decrease of SOFA total from $12.4 \pm$ to $9 \pm 2$, indicating an effective clinical improvement. These data are in agreement with Shum et al. [5], who reported a reduction of SOFA total from 12 to 7.5 and of noradrenaline of more than $40 \%$ at 24 h. Unfortunately, Shum et al. [5] did not evaluate cytokines level or endotoxin, and the study had a small number of cases, so it's difficult to explain the clinical improvement with an anti-inflammatory action of the device.

CRRT with the Adsorbing Filter oXiris in Septic Patients: A Case Series
In our study, in contrary to Shum et al. [5] study, we observed a decrease of IL- 6 during the treatment. This is expected, not only by the properties of the adsorbing membrane but also from many clinical studies in which the increase of IL- 6 correlates with the development and the severity of AKI [11]. We found also a decrease of IL10 , confirming the Malard's results in vitro.

In addition to the effect on the cytokine level, the oXiris filter may adsorb the endotoxin. Recently, Broman et al. [6] found that oXiris adsorbs endotoxin more than AN69ST and that either filters decrease many cytokines. In our case series, endotoxin also decreased from $0.74 \pm 0.15$ to $0.58 \pm 0.18, \mathrm{EAA} /$ unit although we used a different method of measurement (chemiluminescence vs. turbidimetric method), included in our study patients with Gram-positive bacterial infection or mixed infection, and used the filter for longer time than in the Broman's study.

All these effects of the oXiris membrane translate in this case series in an improvement of the hemodynamic, the respiratory function, and of lactate metabolism. These data are in agreement with experimental study on animals, many studies with the AN69ST, and some observational case series [12]. The effect may stem from the effect of the cytokines on the myocardial function, the effect on the NO and other mediators, and the improvement of the fluid balance. The dosage of noradrenaline is also decreased, as shown by Shum et al. [5] and Tengattini et al. [12].

Although recently, the effect of the perfusion pressure on the renal function during the sepsis has been challenged, the continuous adrenergic stimulation may be detrimental during sepsis. In this way, the effect of the oXiris on noradrenaline requirement is positive, as it may decrease the sympathetic storm, improve the immunological response, and the splanchnic perfusion [13].

In summary, data of these case series confirm that CRRT with the membrane adsorbing oXiris may be useful during septic/septic shock, first of all when AKI develops. We did not report any adverse events and observed an improvement of the kidney function and of the cardiorespiratory function, as described on animal's model. This effect is in part linked to the immunological action of the filter itself on the cytokines and the endotoxin. Obviously, these results must be evaluated in the contest of many limitations.

First, this study is only a case series, although we enroled more patients whom Shum's study. We have no control group, and subsequently, it's impossible to draw 
any conclusion about the efficacy of this adsorbing membrane.

We enroled also many patients with a cytokine storm and AKI. We can't suppose whether the oXiris filter may be equally effective if the patients are not in AKI and don't have a proinflammatory response. Third, we enrolled patients using older criteria then SEPSIS 3 conference, in which lactate measurement is warranted. We can't exclude that some patients in this study had lactate measurement in the normal range and were not septic according to the new criteria. Fourth, we observed a decrease in the endotoxin in our case series. As Borman found that the oXiris filter captures the endotoxin only in the first 8 $h$ of perfusion, we can't exclude that in some patient of this study, the filter was partially saturated, when EAA was measured and then the results must be evaluated with caution.

Finally, it is well known that the adsorbing membranes may capture many antibiotics. Although we adjusted the dosages on the data of CRRT, probably many patients had low antibiotic concentration, as many recent studies reported for septic patients during CRRT [14]. In this way, sepsis may worsen, despite the effect of the filter.

\section{Statement of Ethics}

The author has no ethical conflicts to disclose. The author received honorary and travel reimbursement for Internationals and national meetings by Baxter, Medtronic BellcoApheretica, Bi Braun, and Edwards Medical.

\section{References}

1 Dellinger RP, Bagshaw SM, Antonelli M, Foster DM, Klein DJ, Marshall JC, et al.; EUPHRATES Trial Investigators. Effect of Targeted Polymyxin B Hemoperfusion on 28Day Mortality in Patients With Septic Shock and Elevated Endotoxin Level: The EUPHRATES Randomized Clinical Trial. JAMA. 2018 Oct;320(14):1455-63.

2 Schädler D, Pausch C, Heise D, Meier-Hellmann A, Brederlau J, Weiler N, et al. The effect of a novel extracorporeal cytokine hemoadsorption device on IL-6 elimination in septic patients: A randomized controlled trial. PLoS One. 2017 Oct;12(10):e0187015.

3 Rimmelé T, Assadi A, Cattenoz M, Desebbe O, Lambert C, Boselli E, et al. High-volume haemofiltration with a new haemofiltration membrane having enhanced adsorption properties in septic pigs. Nephrol Dial Transplant. 2009 Feb;24(2):421-7.

4 Malard B, Lambert C, Kellum JA. In vitro comparison of the adsorption of inflammatory mediators by blood purification devices. Intensive Care Med Exp. 2018 May;6(1): 12.

5 Shum HP, Chan KC, Kwan MC, Yan WW. Application of endotoxin and cytokine adsorption haemofilter in septic acute kidney injury due to Gram-negative bacterial infection. Hong Kong Med J. 2013 Dec;19(6):4917.

6 Broman ME, Bodelson M. Endotoxin And Cytokin Reduction Function Of The Oxiris Filter In A Prospective Double-Blinded Cross-Over Setting In Patients With Critical Gram-Septic Shock And Continuous Renal Replacement Therapy Requiring Acute Kidney Injury. Intensive Care Medicine Experimental. 2018;6(Suppl 2):0624.

7 Turani F, Busatti S, Martini S, Falco M, Gargano F, Barchetta R. Renal Replacement Therapy With The Oxiris Filter Decreases Inflammatory Mediators And Improves Cardiorenal Function In Septic Patients Better Then Cvhdf.A Cohort Study And A Propensity-Matched Analysis. Crit Care. 2018;22 Suppl 1:148.

8 Hattori N, Oda S. Cytokine-adsorbing hemofilter: old but new modality for septic acute kidney injury. Renal Replacement Therapy. 2016;2(1):41.

9 Gomez H, Ince C, De Backer D, Pickkers P, Payen D, Hotchkiss J, et al. A unified theory of sepsis-induced acute kidney injury: inflammation, microcirculatory dysfunction, bioenergetics, and the tubular cell ad- aptation to injury. Shock. 2014 Jan;41(1): 3-11.

10 Jin K, Murugan R, Sileanu FE, Foldes E, Priyanka P, Clermont G, et al. Intensive Monitoring of Urine Output Is Associated With Increased Detection of Acute Kidney Injury and Improved Outcomes. Chest. 2017 Nov; 152(5):972-9.

11 Payen D, Lukaszewicz AC, Legrand M, Gayat E, Faivre V, Megarbane B, et al. A multicentre study of acute kidney injury in severe sepsis and septic shock: association with inflammatory phenotype and HLA genotype. PLoS One. 2012;7(6):e35838.

12 Tengattini M, Prato F, Colageo U, Pissaia C. Hemodinamic Monitoring During Continuous Renal Replacement Therapy (CRRT) With Oxiris Filter In Septic Shock Patients. Intensive Care Medicine Experimental. 2018; 6(Suppl 2):0301.

13 Stolk RF, van der Poll T, Angus DC, van der Hoeven JG, Pickkers P, Kox M. Potentially Inadvertent Immunomodulation: Norepinephrine Use in Sepsis. Am J Respir Crit Care Med. 2016 Sep;194(5):550-8.

14 Shaw AR, Chaijamorn W, Mueller BA. We Underdose Antibiotics in Patients on CRRT. Semin Dial. 2016 Jul;29(4):278-80. 